\title{
Release and antimicrobial activity of silver sulphadiazine from different creams
}

\author{
J. J. M. van Saene, J. F. G. Trooster, A. M. C. Meulenhoff and C. F. Lerk \\ Laboratory for Pharmaceutical Technology and Dispensing, State University, \\ Groningen, The Netherlands
}

\author{
A. Bult \\ Department of Chemical Pharmacy, University of Utrecht, The Netherlands
}

\begin{abstract}
Summary
The release and antimicrobial activity of silver sulphadiazine from live different creams were studied: unguentum emulsilicans aquosum, unguentum hydrophy. licum nom iomogenicum. parallin cream (1.5 per cent), a homemade preparation and a commercially available preparation (Flamazine). A dilfusion cell was used to measure the releasc and the agar well dilfusion technique to determine the antibacterial activity of the silver sulphadiazinc releiased. The parallion cream (15 per cent) preparaition had the highest relcase ratc. followed by the heoncmide cream and the commercially available creann. The antibacterial activity ran parallel with the release results. This study shows the silver sulphiadiazine parallin cream (o) be superior to the other lour preparations. including the commercially available silver sulphadiazinc cream. using relcalsc and antibaceterial activity ats critcria.
\end{abstract}

\section{INTRODUCTION}

BURN wound sepsis remains one of the major causes of death in burn victims. The main method of controlling burn wound sepsis is by using an appropriate topical antimicrobial agent. Silver sulphadiazine cream is commonly used in burn treatment to prevent bacterial colonization and infection of the wounds (Richards and Mahlangu, 1981; Pegg. 1982). The release of silver sulphadiazine from the cream base determines the bacteriostatic and bactericidal activity. The rate of release of the solid drug suspended in a cream base is determined by several factors. solubility being one of the most important (Itiguchi, 1961). In the literature, no data were found concerning the rate of release of silver sulphadiazine. Therefore, the basic aim of this investigation was to determine the release of silver sulphadiazine from the commercially available cream Flamazine (Duphar. Weesp. The Netherlands), and to compare the release from this industrial cream with four homemade hydrophilic cream bases, mixed with $I$ and 2 per cent silver sulphadiazine (Raunio et al., 1980; Lippold and Teubner, 1982).

Next. the antibacterial activity of the five creams. Flamazine and four homemade creams, was investigated. Finally, the practical applicability was measured using rheological parameters (Colnago et al., 1982).

\section{MATERIALS AND METHODS \\ Materials \\ Cream bases}

Five creams were tested: the commercially available silver sulphadiazine (Flamazine, 82C26) and four homemade hydrophilic creams, which were: unguentum emulsificans aquosum (Deutsches Arzneibuch (1978) 8. 436). unguentum hydrophilicum non ionogenicum (Pharmacopoeia Helvetica (1981) vi, 685d), paraffin cream 15 per cent (Briedes. 1983) and preparation IV. The composition of these creams is shown in Table I. All the substances for the cream bases were of pharmacopoeial purity. Three cream bases were prepared as described in the quoted articles. For preparation IV (own formulation) the water 
Table 1. Composition of the four cream bases

\begin{tabular}{lr}
\hline Unguentum emulsificans aquosum & \\
Alcohol cetostearylatum & $9 \%$ \\
Paraffin subliquidum & $10.5 \%$ \\
Vaselinum album & $10.5 \%$ \\
Aqua & $70 \%$ \\
Unguentum hydrophylicum non ionogenicumt & $10 \mathrm{~g}$ \\
Cetanolum & $20 \mathrm{~g}$ \\
Oleum arachidis hydrogenatum & $\mathbf{5 g}$ \\
Polysorbatum monostearylatum & $20 \mathrm{~g}$ \\
Propylenglycolum & ad $100 \mathrm{~g}$ \\
Aqua & \\
Paraffin cream 15\% & $254 \mathrm{~g}$ \\
Carbomer watergel 1\% & \\
Polysorbate 80/sorbitan mono-oleate & $1 \mathrm{~g}$ \\
$\quad$ mixture aa & $\mathbf{4 5 \mathrm { g }}$ \\
Paraffin subliquidum & \\
Preparation IV & $5 \mathrm{~g}$ \\
Alcohol cetostearylatum & $\mathbf{9 g}$ \\
Glycolum monostearylatum & $10 \mathrm{~g}$ \\
Propylenglycolum & $10 \mathrm{~g}$ \\
Paraffin subliquidum & $2.5 \mathrm{~g}$ \\
Tween 60 & $2.5 \mathrm{~g}$ \\
Tween 80 & ad $100 \mathrm{~g}$ \\
Aqua & \\
\hline
\end{tabular}

- Deutsches Arzneibuch (1978) 8, 436.

† Pharmacopoeia Helvetica (1981) VI, 685d.

\$ Pharmaceutisch Weekblad.

5 Own preparation.

phase and fat phase were heated separately in a water-bath at $70^{\circ} \mathrm{C}$. The water phase was added to the fat phase and the emulsion was stirred until the cream reached room temperature. The volume of water lost by evaporation was replaced. All these creams were prepared without preservatives. Silver sulphadiazine was suspended in the cream bases after fine grinding in a mortar and pestle. The concentrations in the four homemade preparations were 1 and 2 per cent silver sulphadiazine respectively.

\section{Silver sulphadiazine}

A commercial grade of silver sulphadiazine was used (ACF, Chemiefarma. Maarsen. The Netherlands; charge 780472/80)E(01). The particle size, given by the manufacturer, was: 100 per cent of the particles $<50 \mu \mathrm{m}, 99$ per cent $\leqslant 20 \mu \mathrm{m}$ and 90 per cent $\leqslant 10 \mu \mathrm{m}$.

\section{Methods \\ Determination of the release}

The in vitro release of silver sulphadiazine from different cream bases was studied by means of a diffusion cell (Fig. 1). The circular cell consisted of a ring (A) and a dish (B) of polymethacrylate.

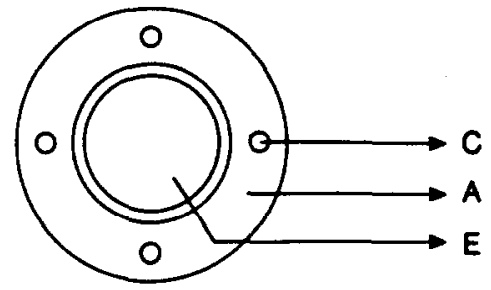

UPPER-SIDE

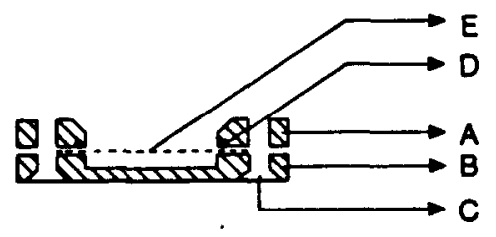

CROSS-SECTION

Fig. I. Diffusion cell used for relcase experiments. A. a ring: B. a dish al pulymethacrylate: ( . serews; D. perspex O-ring: E, cellulose membranc.

The dish had a circular well (inner diameter $30 \mathrm{~mm}$, depth $3 \mathrm{~mm}$ ), which could be filled with cream. The excess cream was removed using the edge of a spatula to produce an even uniform surface of constant dimensions. A membrane (E) wetted with acceptor medium was placed over the surface of the dish containing the cream, in such a way as to avoid air bubbles in the cell. The semipermeable membrane consisted of cellulose with a molecular weight cut-off of $12(x)(x)-14(x))$ daltons (Spectra Mcdical Industrics. Los Angeles. USA). The membrane was maintained in a that position using a perspex (O-ring (D) between the ring $(A)$ and the dish (B). The ring of the diffusion cell was fixed with screws (C) onto the dish.

The diffusion cell was placed at the bottom of a $250 \mathrm{ml}$ beaker, filled with $2(K) \mathrm{ml}$ acceptor medium. An isotonic phosphate-buffered solution. pll=7.4 (Dulch Pharmacopocia (1978) \&. 256), wis used as acceptor medium. The beaker was kept in a constant-temperature water-bath maintained at $32^{\circ} \mathrm{C}$. The acceptor medium was stirred with a four-bladed stirrer $(l=50, h=10 \mathrm{~mm})$, which was driven by a synchronous motor at $50 \mathrm{r} / \mathrm{min}$. The distance between the diffusion cell and the stirrer was $4(1) \mathrm{mm}$. The diffusion cell was placed in the heaker at the beginning of the experiment. During a period of $6 \mathrm{~h}$ a $3 \mathrm{ml}$ simple was taken every 3 (3) min. Throughout the release run, the volume of the acceptor medium was kept constant by replacing the sample removed with an equal volume of acceptor 
medium. The samples were ansilyed with a Beckmann ultraviolet spectrophotometer at $242 \mathrm{~nm}$

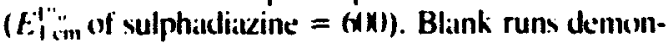
strated the minimal presence of material in the external solution that might interfere with the meisurements. All results were corrected for these deviations.

\section{Data treatment}

Each release experiment was performed at least four times and the averaged data were used to plot the amount of drug released (into $2(X) \mathrm{ml}$ acceptor medium) per unit of area $\left(\mathrm{cm}^{2}\right)$ versus the time and the square root of time respectively. The correlation coefficient wats calculated for the square roset of time plots.

\section{Microbiological evaluation}

The agar-well diffusion technique described by Nathan et al. (1977) was used to evaluate the antimicrobial activity of identical concentrations of silver sulphadiazine in the five different creams. This diffusion technique was chosen since it incorporates the evaluation of the drug carriers which are critical factors for the antibacterial activity of topical agents (i.e.. silver sulphadiazine). This in vitro method includes the following steps:

\section{(1) Test plate preparation}

A petri dish. $9(1) \mathrm{mm}$ in diameter. was filled with $1.5 \mathrm{ml}$ of agar containing standard hrain-heart infusion (BIII) (BLBL. Becton Dickinson and (')mpally. (inckeysville. USA. Art. II(K,5). Five holes. Ymm in dianeter. were malele in the agar by removing plugs cut with a cork-borer. The holes. evenly distributed on the plate. were spaced about $20 \mathrm{~mm}$ apart and $15 \mathrm{~mm}$ from the outer edge. All procedures were performed using sterile instruments to avoid contamination of the petri dish. Five separate syringes were filled with the five different silver sulphadiazine creams, and I8 gauge needles were attached to each syringe.

To evaluate the relation between the drug activity and the amount of drug. different amounts of silver sulphadiazine cream were tested: $10 \mathrm{mg}$. $20 \mathrm{mg}$. $30 \mathrm{mg}$. $410 \mathrm{mg} .50 \mathrm{mg}$ and 6) $\mathrm{mg}$ of silver sulphadiazine cream per well. Each hole of a petri dish was filled with $10 \mathrm{mg}$ of the five different creams: second, third, fourth. fifth and sixth petri dishes were filled with $20 \mathrm{mg}$. $30 \mathrm{mg}$. 41$) \mathrm{mg}$. $50 \mathrm{mg}$ and $60 \mathrm{mg}$, respectively, of each cream. The loaded syringes were weighed. an approximate amount of cream was extruded into the centre of each hole on the agar plate and each syringe was weighed again.
(2) Plate inoculation with a bacterial strain Seven millilitres of melted BIIl algar (at approximately $45^{\circ} \mathrm{C}$ ) was mixed with $1 \mathrm{mI}$ BHI broth containing $10^{n}$ bacteria per $\mathrm{ml}$. The bacterium used for inoculation was Pscudomonas aeruginosa. The test strain was maintained on agar slopes and transferred to the fluid $\mathrm{BHI}$ broth using a wire loop. The strain was incubated at $37^{\circ} \mathrm{C}$ for $18 \mathrm{~h}$. leading to a pure culture suspension of $10^{\prime \prime}$ colony forming units (CFU) per $\mathrm{ml}$ of broth. The suspension of melted agitr and hacterial was mixed on a mechanical agitateor and poured onto the previously prepared live plates containing the five different creams (o be tested. The holes were complefely filled with the agar and the overlay was evenly distributed.

\section{(3) Silver sulphadiazine concentrations}

Two concentrations of silver sulphadiazine ( I and 2 per cent) were used in the four homemade creams. The commercially available cream contained 1 per cent silver sulphadiazine only.

\section{(4) Incubation}

The fluid agar overlay, containing the suspension of hacteria, solidified in about 1 min. The test plates were incubated at $37^{\circ} \mathrm{C}$ for $18 \mathrm{~h}$.

\section{(5) Reading the test plates}

A clear arcit containing no colonies around a lest well following the incubation period indicated that the drug was hactericidal against /'s. acrugimoxu. The size of the eleatred areats and the cream areals were measured with a marking gallge. The dianeter (mm) of the clear areat wats determined by subtracting the creatm dianceter from that of the clear arcia.

\section{Rheological evaluation}

Rheograms were obtained using a rotational viscometer type Rotovisko RV 3, a conc and plate viscosity sensor system PK I in combination with a measuring head MK 5(X). A constant-temperature circulator (type FK) maintained the samples at a constant temperature of $32^{\circ} \mathrm{C} \pm(1) \cdot\left(12^{\circ} \mathrm{C}\right.$ (llatake. D-Karlsruhe). In order to ensure that all the creams had been subject to the same shear history". the same preparation and kading procedures were employed in all experiments. Very small samples were transferred with a spatula onto the plate. taking care that no air bubbles were present. The flow curves were measured using a time linear $\mathrm{r} / \mathrm{min}$ programme of $4(x) \mathrm{r} / \mathrm{min}$. 


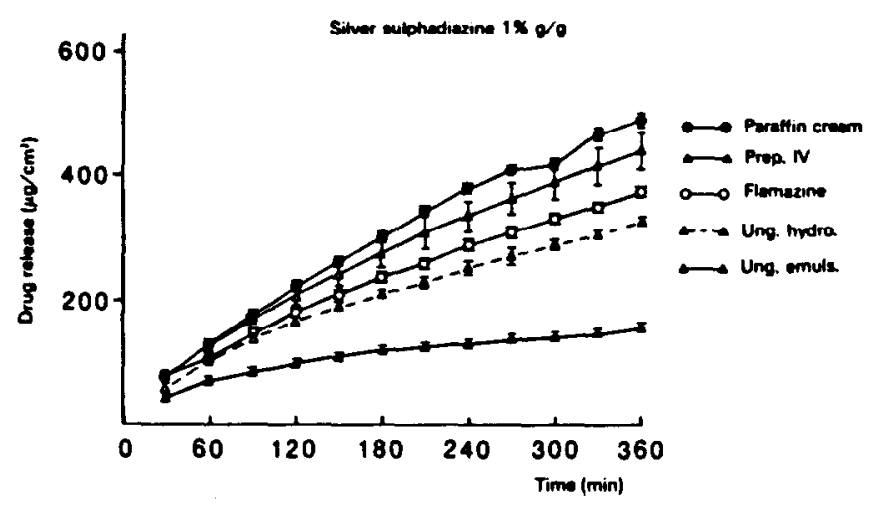

(a)

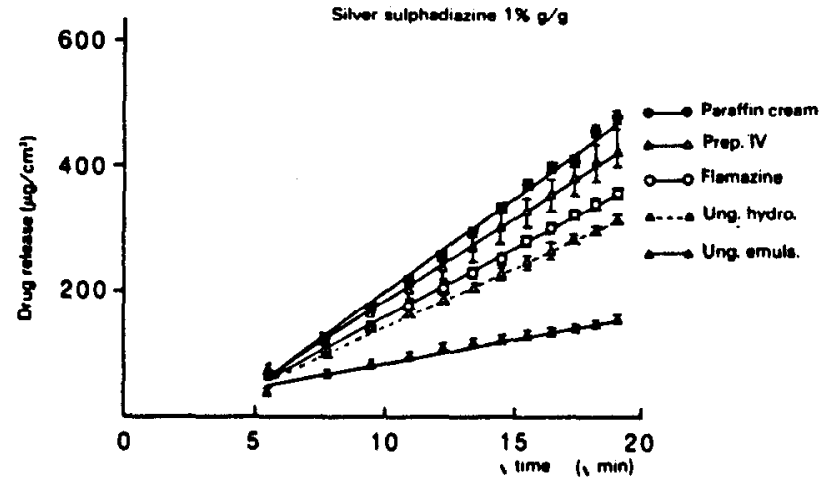

(b)

Fig. 2. Release ( $\left.\mu \mathrm{g} / \mathrm{cm}^{2}\right)$ of silver sulphadiazine from different cream bases (1 per cent $g / g$ ) vs. time (min) $(a)$ and vs. the square root of time (b).

\section{Statistical evaluation of data}

For each experiment, statistical differences were asseessed using Student's 1 test and comparing experimental points corresponding to identical values on the axis. A significant difference between two bases was assumed to exist if all experimental points. except the lirst pair $(1 \mathrm{~h})$. were significantly different at the 5 per cent level (Armitige, 1974).

\section{RESULTS \\ Release}

Figs. 2 and 3 show the results of release from the different cream bases mixed with silver sulphaldiazine at concentrations of 1 per cent and 2 per cent respectively. The amount of silver sulphadiazine released from the bases was plotted in Figgs. $2(a)$ and $3(b)$ vs. the time and in Figgs. $2(b)$ and $3(b)$ vs. the square root of time. The slopes between the different creams were all significantly different at a $P$ value of less than 0.115 for both concentrations. The slope between Flamazine and paraffin cream was signiticantly different
$(1 /<1) \cdot 12)$. A fictor of about $1 .+$ was found between the amount of silver sulphadiazine released from the creams containing 1 per cent and 2 per cent of the drug.

\section{Antimicrobial activity}

The paraffin cream bases, containing I per cent and 2 per cent silver sulphadiazine respectively, both showed the best antimicrobial activity (Fig. 4). Thirty milligratms of silver sulphadiazine paraflin cream per well gave the maximal effect in the vitro test system. This amount was also found for the other bases, with the exception of ung. emulsificans and ung. hydrophylicum which showed a greater zone in relation to a higher amount of silver sulphadiazine cream. The slopes between paraftin cream, I per cent silver sulphadiazine and the other creams mixed with I per cent silver sulphadiazinc were significantly different, including Flamizine $(P<0.155)$.

\section{Rheological evaluation}

The dependence of shear stress on the rate of shear for the creams was measured, and some 

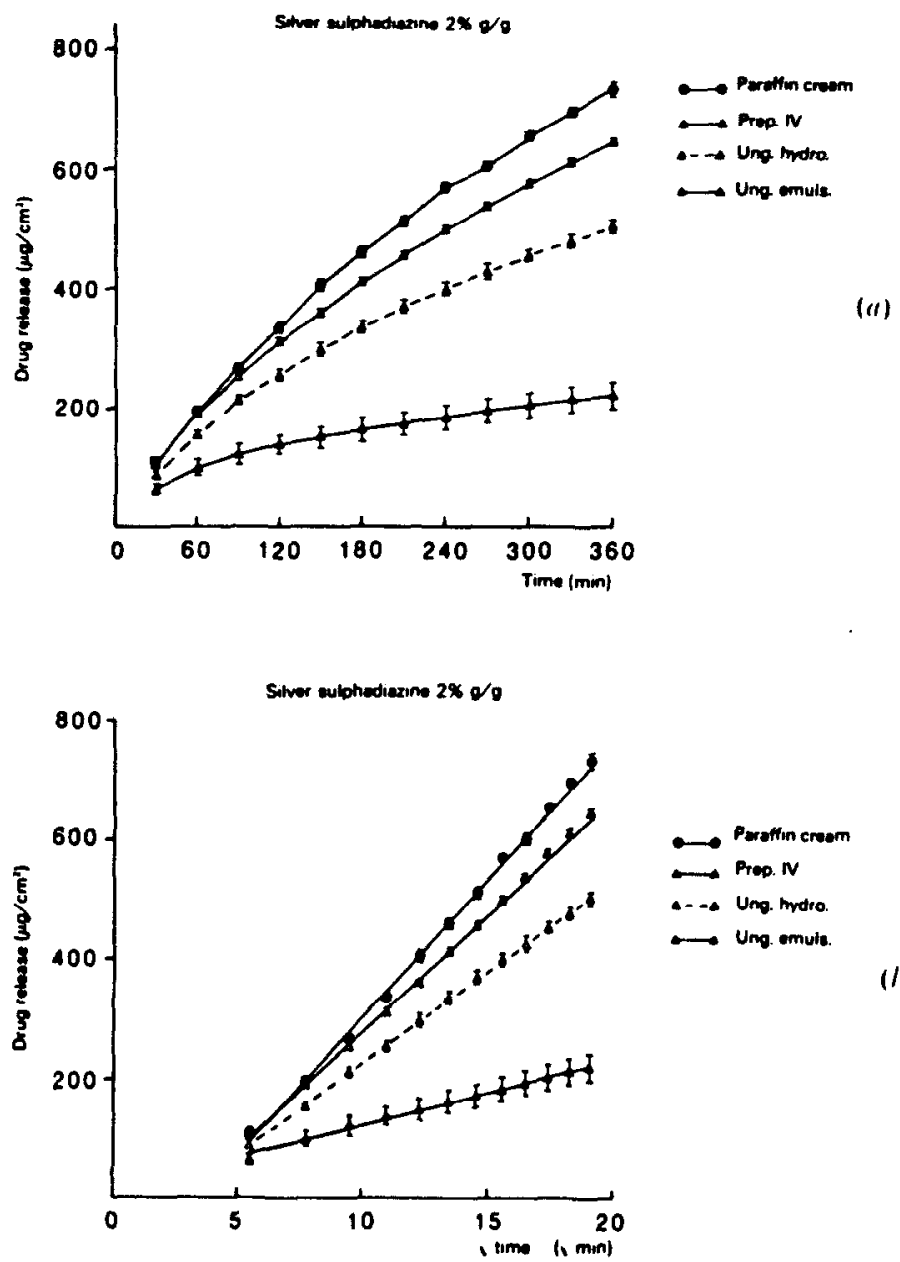

(1)

Fis. 3. Releiasc $\left(\mu \mathrm{g} / \mathrm{cm}^{2}\right)$ of silver sulphadiazinc from different cream hases (2 per cent. $g / g)$ vs. lime (min) (a) and vs, the square root of time (b).

characteristic rheograms are shown in Fig. 5 . The 'up' and 'down' curves were not identical, showing a considerable thixotropic behaviour in some creams. The paraffin cream had a pseudoplastic character also.

\section{Discussion}

The diffusion cell used in this study to measure the release of silver sulphadiazine was found to yield reproducible results. The relative standard deviation in the different determinations had an average value of 7 per cent. When the amounts of silver sulphadiazine released were plotted vs. the square root of time, straight lines were obtained with a good correlation coeflicient (Table (I). The plots in Figss. 2(b) alld $3(b)$ never patssed through the origin. The prexence of a lag time for the rekeiase of a drug across an artiticial membranc has been reported earlier (Bottari et al.. 1974). This phenomenon has been associated with the presence of the membrane. separating the bulk phase from the sink.

This stucly shows the parafin hatse to be significantly superior to Flamazine cream from both the technological and microbiological point of view. The release from paraffin was found to be 1.5 times higher and the diameters of the cleared zones were about $4.8 \mathrm{~mm}$ compared to $3.6 \mathrm{~mm}$ for Flamazine. From the rheological point of view paraffin 'spreadability' is as good as that of Flamazine. Another factor which should be taken into 

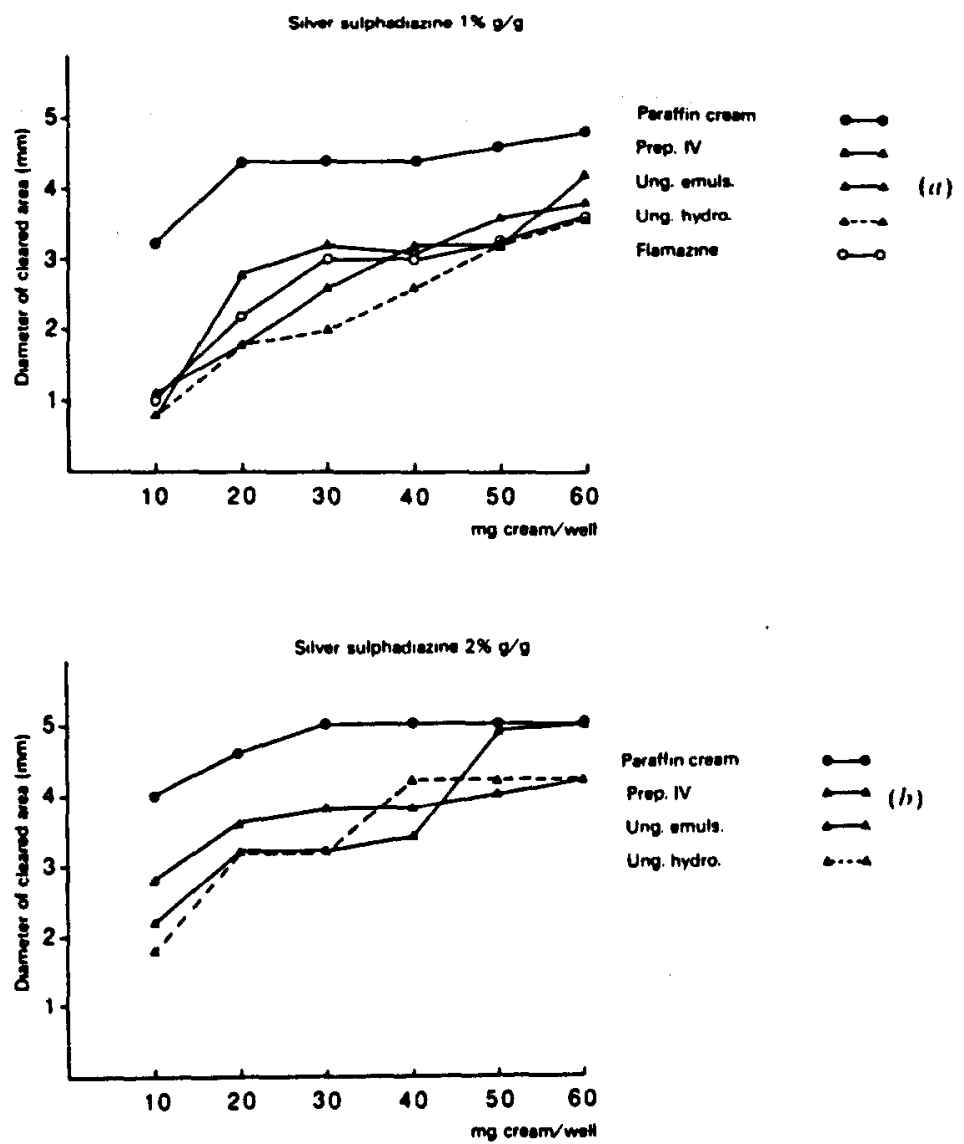

Fig. 4. The plot for the diameter of cle:ared area $(\mathrm{mm})$ in the agar diffusion test with different cream hases containing I per cent silver sulphadiazinc $(g / g)(a)$ and 2 per cent silver sulphidiazine $(g / g)(b)$ in the presence of Pseadomomas aeruginosa.

Table 11. Correlation coefficients of silver sulphadiazine release from the different creams vs. time

\begin{tabular}{|c|c|c|}
\hline Cream & $\begin{array}{l}\text { Silver sulp } \\
1 \text { per cent g/g } \\
\text { (fig. } 2(b))\end{array}$ & $\begin{array}{l}\text { phadiazine } \\
2 \text { per cent g/g } \\
\text { (Fig. } 3(b))\end{array}$ \\
\hline $\begin{array}{l}\text { Paraffin cream } \\
\text { Prep. IV } \\
\text { Flamazine } \\
\text { Ung. hydro. } \\
\text { Ung. emuls. }\end{array}$ & $\begin{array}{l}0.9966 \\
0.9984 \\
0.9978 \\
0.9998 \\
0.9912\end{array}$ & $\begin{array}{c}0.9983 \\
0.9990 \\
0 . \overline{9998} \\
0.9968\end{array}$ \\
\hline
\end{tabular}

account is the toxicity of additives to creams: for example. emulsifying agents carboxypolymethylene and sorbitan derivatives. Toxicity has not been described for the low concentrations used in both the paraftin and Flamazine creams (Marrindulc, 1982).
The introduction of Flamazine by Fox (1968) has led to a remarkable improvement in the management of burn wounds. Different clinical studies show that Flamazine is a valuable topical cream for the prevention of burn wound infection (Fox. 1968: Stanford et al.. 1969; Lowbury et al., 1971). However, careful microbiological studies have revealed that Flamazine does not prevent colonization by Staphylococcus aureus and $P s$. aeruginosa (Gayle et al.. 1978: van Saene and Nicolai. 1979). These observations can be explained by the relatively low concentrations of antibacterially active silver sulphadiazine. due to: (i) minimal inhibitory concentrations (MICs) of the agent. (ii) the small amount released from the cream base and (iii) inactivation of the agent by proteins. The MICs of silver sulphadiazine for most clinically important bacteria are relatively high: 50-1(K) $\mathrm{mg} / \mathrm{l}$ (van Saene et al., 1983). 

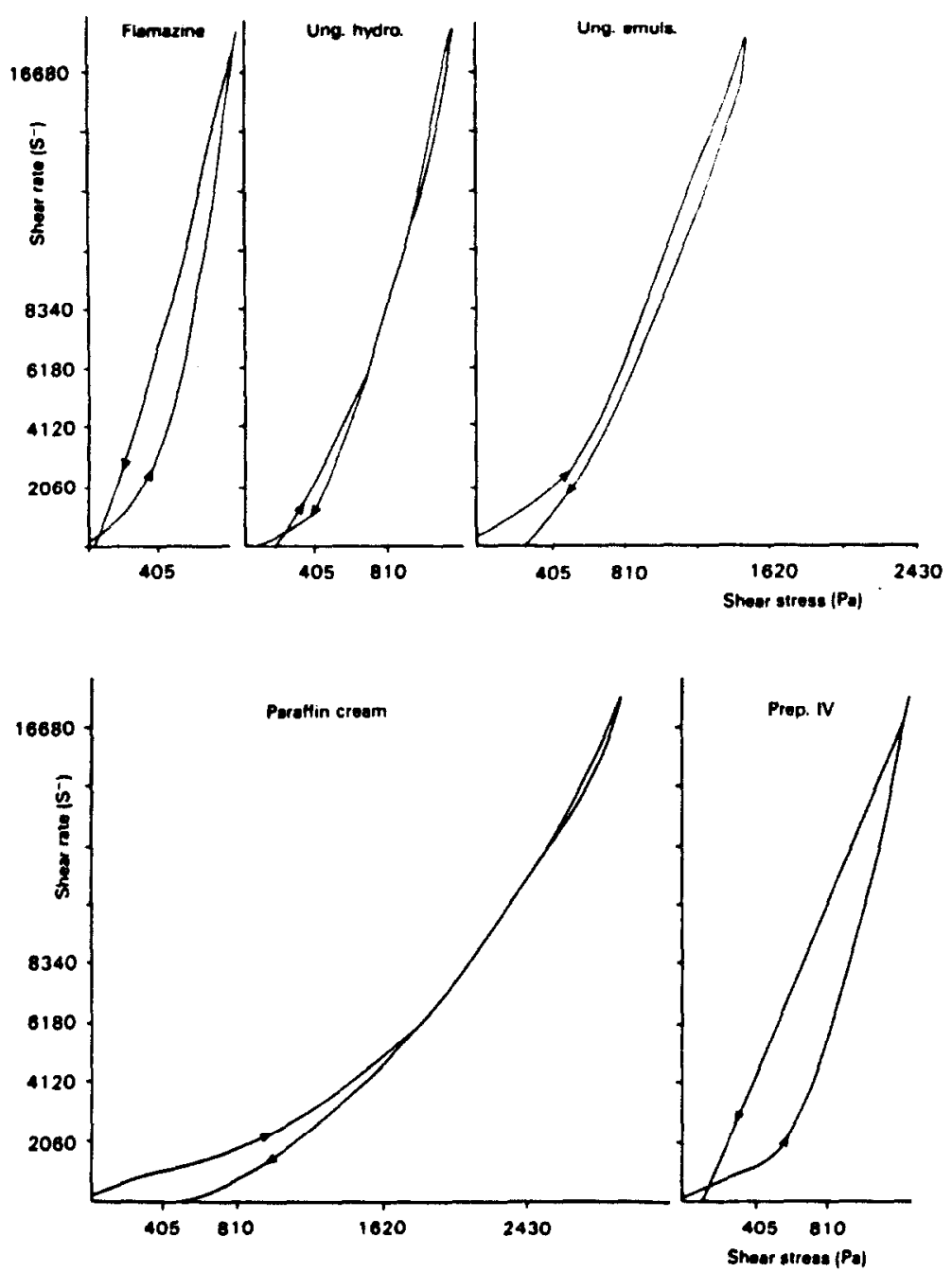

fig. S. Shear rate (S) dependent on stress of shear for different cream bases containing 1 per cent silver sulphadiazinc.

Secondly, the release rate is found to be about $50 \mu \mathrm{g} / \mathrm{cm}^{2} /$ per h. Thirdly, silver sulphadiazine is known to be bound by proteins and necrotic tissuc covering burn wounds (Bult, 1982). The theory of Fox and many others is that silver sulphadiazine is present in gross excess on the wound which alters the MIC, release rate and protein inactivation problems. High rates of bacterial colonization of wounds covered with Flamazine do not correlate with this theory. We believe that the satisfactory clinical results with Flamazine - which is alsu our daily experience should be attributed primarily to the covering effect of the base (substituting damaged skin and preventing loss of thuids and proteins) and less to the antibacterial effect of silver sulphadiazine. An antibacterially more active disinfecting agent added to a paraffin cream base with identical rheological and technological properties as Flamazine. but characterized by a higher release rate. seems to us to be more promising in the management of burn wounds.

\section{Acknowledgements}

The authors would like to express their thanks to Mr J. Duitsch for redrawing the ligures. to Dr HI. Proost for carrying out the statistical analyses and to Miss I. Brown for reading the manuscript. 


\section{REFERENCES}

Armitage P. (1974) Statistical Methods in Medical Re. scurch. Oxlourd. Blackwell Scientific. p. 21 .

Bottari F., Di Colo G.. Nannipierri E. et al. (1974) Influence of drug concentration on in vitro release of salicylic acid from ointment hases. $J$. Pharm. Sci. 63, 1779.

Bricde R. H. (1983) Tocpassingen van carbomeerwatcergel 1"\%. 1'harm. We'sht. I18. 17II.

Bult A. (1982) Silver sulphadiazine and related antihacterial metal sulfanilamicles: liacts and limey. Pharm. Int. 3, 4(X).

Colnago F.. Stivic I. and Jalsenjak 1. (1982) Drug release and theological characteristics of oleaginous ointments. Acfo Pharm. Technol. 28, 61.

Fox (. L. (I)(ns) Silver sulladiazinc - a new topical therapy for Piscudemonas in burns. Arch. Surg. 96. 184.

Gayle W. E., Mayhall C. G.. Lamb V. A. el al. (1978) Resistant Enterobacter cloacue in a hurn centre: the incffectiveness of silver sulfadiazine. J. Tranma 18 , 317.

Higuchi T. (1961) Rate of relcasse of medicaments I'rom ointment bases containing Jrugs in suspension. J. Pharm. Sici. 50, 874.

Lippold B. C. and Teubner A. (1982) In virro freizet. zung von nicotinsalurebenzylesfer ales verschiedenen lösungssillicn. Acka Pharm. Tochnol. 28, 115.
Lowbury E. J. L.. Jackwon. D. M.. Ricketts. C. R. et al. (1971) Topical chemoprophylaxis for hurns: trials of creams containing silver sulphadiazine and trimethoprim. Injury 3, 18 .

Martindale. The Extra Pharmacopocia (1982) London. The Pharmaceutical Press. pp. 376. 950,

Nathan P.. Law E. J.. Murphy D. F. ct al. (1977) A laboratory method for selection of topical antimicrobial agents to treat infected hurn wounds. Burns 4, 177.

Pegg S. P. (1982) The role of drugs in management of hurns. Drugs 24, 256.

Raunio O.. Juslin M. and Juutlainen P. (198(1) Effect of topical vehicle composition on the release of tolfenamic acid in vitro. Acta Pharm. Fenn. 89, 267.

Richards R. M. E. and Mahlangu G. N. (|98|) Therapy for burn wound infection. J. Clin. Hoxp. Pharm. 6, 23.3.

Stanford W.. Rappole B. W. and Fox C. L. (1969) Clinicil experience with silver sullatiazine. $J$. Traumu 9. 377.

van Sacne H. K. F. and Nicolai J. P. A. (1974) The prevention of wound infections in burn patients. Sictul. J. I'last. Recomsur. Surs. 1.3, 6.3.

van Silcne J. J. M.. Bult A. and Lerk C. F. (1983) Novel techniques for determination of antibacterial activity of silver sulfanilamides. Pharm. Weckhl. |Sci./ 5, hl.

Paper incipuled I Augus lusk.

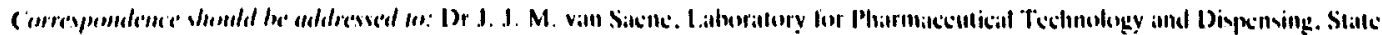

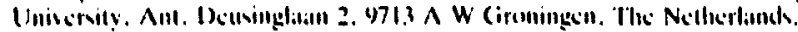

